\title{
CIRCUITOS CURTOS DE COMERCIALIZAÇÃO E NOVOS USOS DOTERRITÓRIO: CONSIDERAÇÕES SOBRE O PNAE E AS FEIRAS LIVRES
}

\author{
Anelise Graciele Rambo* \\ Luciana Pozzebom** \\ Eduardo von Dentz****
}

\begin{abstract}
Resumo
O processo de modernização da agricultura, sobretudo no Brasil, imprimiu sobre o território, novos usos, e pressionou muitos agricultores familiares a encontrarem novas alternativas de produção e geração de renda. $\mathrm{O}$ debate acerca do reconhecimento do papel dos circuitos curtos de comercialização, promovidos por agricultores familiares, sua capacidade de promover novos usos do território, e seus reflexos sobre o desenvolvimento rural, está inserido neste contexto de exclusão e surgem como uma alternativa ao modelo padrão de tecnificação do espaço rural. Assim, serão apresentados a seguir, dois exemplos de circuitos curtos de comercialização existentes em Santa Catarina, indicando como estes circuitos promovem novos usos do território. Os casos referidos dizem respeito aos mercados promovidos pelo Programa Nacional de Alimentação Escolar (Pnae), bem como às feiras livres de Chapecó. Com tais exemplos, pretendemos chamar atenção para a importância de diferentes formatos de circuitos curtos de comercialização, os quais demonstram inicialmente, estarem promovendo usos agrícolas e não agrícolas no espaço rural, agregando às dinâmicas locais de desenvolvimento, capacidades potencializadoras da base de recursos através da diversificação produtiva e da geração de renda. Isso implica o reconhecimento e o fortalecimento de um espaço rural mais diversificado e sustentável econômica, social e ambientalmente.
\end{abstract}

Palavras-chave: Agricultura familiar. Circuitos curtos. Uso do território. Produção de alimentos.

\footnotetext{
* Doutora em Desenvolvimento Rural (UFRGS), Docente da Universidade Federal do Rio Grande do Sul (UFRGS) - (campus Litoral).E-mail: ane_rambo@yahoo.com.br

** Especialista em Segurança Alimentar e Nutricional - Universidade Federal da Fronteira Sul (UFFS), Chapecó/SC. E-mail: pozzebom@unochapeco.edu.br

**** Doutorando em Geografia pela Universidade Federal de Santa Catarina (UFSC).E-mail: eduardovondentz@hotmail.com
} 


\section{Introdução}

O objetivo deste artigo é demonstrar que os mercados institucionais, como o Pnae, e as feiras livres são maneiras de incentivar os circuitos curtos de comercialização de alimentos, ao mesmo tempo em que acabam impulsionando novos usos do território (SANTOS, 1996). O estudo do território, segundo Santos (1996), somente tem sentido quando analisamos seu uso, isto é, os eventos e as manifestações dos atores sociais que nele acontecem. Os circuitos curtos de comercialização, por sua vez, constituem mecanismos dos quais se vale a agricultura familiar para obter renda, priorizando o trabalho familiar. Destacamos, ainda, que estes circuitos são uma alternativa para comercializar os produtos, permitindo - além de diminuir o número de intermediários entre o produtor e o consumidor - reconectar produtores e consumidores, socializando e espacializando o alimento nas escalas local ou regional (RENTING; MARSDEN; BANKS, 2003,2017; MARSDEN, BANKS, BRISTOW, 2000; FRANÇOIS, 2000).

Considera-se fundamental realizar mais estudos acerca da diversidade de estratégias produtivas e reprodutivas da agricultura familiar e seus estilos enquanto manifestação das distintas trajetórias históricas das mais diferentes regiões do país (SCHNEIDER; MENEZES, 2014). Nesse sentido, no presente trabalho pretende-se tecer considerações sobre os usos do território decorrentes dos circuitos curtos de comercialização mobilizados pelos agricultores familiares que incluem a comercialização de alimentos via Programa Nacional de Alimentação Escolar (Pnae) e as feiras livres - os quais inicialmente se mostram enquanto uma alternativa para a geração de renda e uma estratégia importante de desenvolvimento rural.

Dessa maneira, visando ao alcance do objetivo anteposto, o presente artigo foi dividido, além dessa introdução, em três partes: em um primeiro momento, aborda-se o uso do território e a modernização da agricultura no Oeste de Santa Catarina. E um segundo momento, tratar-se-á dos mercados institucionais e das feiras livres como fomentadores de circuitos curtos de comercialização e novos usos do território no Oeste Catarinense. $\mathrm{Na}$ terceira e última sessão, são apresentadas as considerações finais acerca do escopo teórico construído e do empírico abordado.

\section{Uso do território e a modernização da agricultura no Oeste Catarinense}

Na perspectiva de Santos (2002), o território não é apenas o conjunto de sistemas naturais e de sistemas de coisas superpostas. Deve ser entendido como território usado, não território em si. O território usado é o chão 
mais a identidade. $\mathrm{A}$ identidade é o sentimento de pertencer àquilo que nos pertence. Haesbaert (2005) corrobora com tal perspectiva ao discorrer que o território diz respeito às relações econômicas e culturais, pois está intimamente ligado ao modo como as pessoas utilizam a terra, como elas próprias se organizam no espaço e como elas dão significado ao lugar. E complementa Santos (2005, p. 255): “[...] o território são formas, mas o território usado são objetos e ações, sinônimo de espaço humano, espaço habitado".

Por essas razões, às transformações e/ou inovações que ocorreram no território afetam, direta ou indiretamente, todos os setores da economia em diferentes escalas (mundial, nacional, estadual, municipal), ocasionando, consequentemente, uma reestruturação do processo produtivo em também em diferentes escalas. Santos (1996) afirma que a universalização do mundo pode ser constatada na

[...] universalização da produção, incluindo a produção agrícola, dos processos produtivos e do marketing. Universalização das trocas, universalização do capital e de seu mercado, universalização da mercadoria, dos preços e do dinheiro como mercadoria-padrão, universalização das finanças e das dívidas, universalização do modelo de utilização dos recursos por meio de uma universalização relacional das técnicas, universalização do trabalho, isto é, do mercado de trabalho e do trabalho improdutivo, universalização do ambiente das firmas e das economias, universalização dos gostos, do consumo, da alimentação. Universalização da cultura e dos modelos de vida social, universalização de uma racionalidade a serviço do capital, erigida em moralidade igualmente universalizada, universalidade de uma ideologia mercantil concebida do exterior, universalização do espaço, universalização da sociedade tornada mundial e do homem ameaçado por uma alienação total. (SANTOS, 1996, p. 18).

A agricultura moderna, por sua vez, ao se apropriar do território, atrai investimentos com a finalidade de inseri-la de forma competitiva no mercado. Essa competitividade acaba formando regiões que fragmentam o seu entorno e desintegram o restante do território, configurando-se como "ilhas de eficiência produtiva", que em sua maior parte beneficia apenas o "grande" capital.

É importante destacar que essa expansão da agricultura moderna se dá, segundo Balsan (2006), a partir de meados da década de 1960, considerando que vários países latino-americanos se engajaram na chamada "Revolução Verde". Esta Revolução é fundada basicamente em princípios de aumento da produtividade através do uso intensivo de insumos químicos, de variedades de alto rendimento melhoradas geneticamente, da irrigação e da mecanização, criando a ideia que passou a ser conhecida como 
agricultura moderna, agricultura avançada e/ou agricultura tecnificada e geneticamente melhorada.

Segundo Graziano da Silva e Del Grossi (2000), a desigualdade da modernização se expressa em três níveis: entre as regiões do país, entre as atividades agropecuárias e entre os produtores rurais. Frederico (2013, p. 220) ressalta que “[...] os principais beneficiados pela modernização do campo foram os grandes produtores agrícolas, grandes agroindústrias e empresas multinacionais fabricantes de agrotóxicos, maquinário agrícola e do comércio mundial de grãos".

No Oeste Catarinense, por exemplo, a instalação de estruturas produtivas de processamento de carnes, a exportação deste produto, e mesmo a importação de mão de obra, por exemplo, exerce influência sobre a reestruturação da agricultura e sua aproximação do setor de tecnologia, ciência e informação, ocasionando um novo uso do território. Ainda nesta perspectiva, corroboramos com Espíndola (1999) ao afirmar que,

[...] a agricultura passa a ser consumidora de insumos modernos, fornecedora de alimento e campo de investimento para os diferentes capitais. Assim, a partir de 1960, o Oeste catarinense - a exemplo de outras áreas do Centro-Sul brasileiro - foi incorporado ao projeto modernizante edificado pelo Estado, empresas nacionais e multinacionais. (ESPÍNDOLA, 1999, p. 104).

Diante das questões apontadas por Santos (1996) e Espíndola (1999) e, na tentativa de caracterizar o uso do território e no Oeste de Santa Catarina, torna-se indissociável um breve resgate histórico sobre a reestruturação da produção agroindustrial, decorrente da modernização agrícola no Oeste Catarinense.

De acordo com o trabalho de Hentz (2014), a região Oeste de Santa Catarina destaca-se na economia como uma das maiores áreas produtivas globais do setor alimentício, atuando nos segmentos de carnes (frangos, suínos, peru), alimentos processados de carnes, lácteos, margarinas, massas, pizzas e vegetais congelados, cereais etc. As agroindústrias situadas na região Oeste de Santa Catarina, principalmente nas proximidades de Chapecó, formam um sistema hegemônico de produção, industrialização e comercialização. Segundo Reche (2008), o estado de Santa Catarina é o maior produtor e exportador brasileiro de carnes de frango, sendo responsável por 14\% da produção nacional e 28\% das exportações brasileiras.

Ademais, na região Oeste de Santa Catarina, e particularmente no município de Chapecó, a modernização da agricultura se deu através da integração do agricultor familiar às agroindústrias. Segundo Hespanhol (2003), apenas uma parcela de produtores foram integrados a este sistema que representa a articulação da pequena produção ao capital agroindustrial. 
Isso ocorre devido à grande exigência de incorporações tecnológicas. E para aquela parcela de pequenos produtores que não apresentavam as precondições "[...] para se integrarem ou para participarem do processo de modernização, em virtude de seu caráter altamente seletivo, restou à exclusão" (HESPANHOL, 2003, p. 48).

Diante desse cenário, é preciso refletir sobre o atual modelo de desenvolvimento rural. Segundo Campos (1999), este modelo, atrelado a uma dependência tecnológica cada vez maior, tem acarretado consequências profundamente negativas, que vão desde a configuração de um processo crescente de exclusão social e econômica de grande parte da população, até as repercussões ambientais, tais como esgotamento de terras e contaminação ambiental, causando, com isso, um comprometimento da potencialidade produtiva dos recursos naturais de grande parte das terras.

Ademais, de acordo com Hentz (2014), as novas tendências nos processos produtivos agroindustriais conduzem a uma (re)espacialização da produção baseada na verticalização da produção, no uso intensivo de tecnologias de genética, nutrição e processamento da produção. Neste novo contexto, os impactos em termos sociais são evidentes. No processo de deslocamento e concentração da produção, parcela significativa de produtores integrados acabou excluída do processo produtivo em virtude de não atender aos requisitos dos novos modelos de integração. Muitos desses, sem alternativas de produção e/ou comercialização, acabam obrigados a procurar por novas alternativas que propiciem sua emancipação e garantam a sobrevivência destes atores sociais. Os circuitos curtos de comércio estão inseridos neste horizonte de alternativas.

Campos (1999, p. 320) também aponta que se faz necessário pensar e construir um modelo de desenvolvimento rural sustentável, que leve em consideração a importância de se criar "[...] uma estrutura produtiva economicamente eficiente e socialmente equitativa, tendo por base a pequena propriedade agrícola”. Ou seja, trata-se de priorizar as formas de produção, de comércio (circuitos curtos de comercialização) e usos do território que, ao mesmo tempo, assegurarão a manutenção social e econômica da agricultura de pequena escala.

Ao considerar essas dinâmicas socioespaciais decorrentes da Revolução Verde, que excluem parcela dos agricultores, Ploeg (2000) trata do squeeze na agricultura, consequência, em certa medida, de resultados produtivos bem-sucedidos da modernização da agricultura, mas discretos resultados sociais, representando, por vezes, um decréscimo das condições de vida de parte considerável dos agricultores. Frente a esse aperto (squeeze), constitui-se uma heterogeneidade dos processos de mercantilização da agricultura familiar, resultando numa pluralidade de estilos de agricultura (PLOEG, 2000) e de mecanismos de manutenção perante a generalização 
das relações mercantis. Para Ploeg (2000), “[...]os estilos de agricultura podem ser considerados como algumas das muitas respostas para o projeto da modernização [...]”. Alguns estilos representam e reproduzem a internalização do projeto de modernização (e são materialmente dependentes de sua continuação). Outros estilos, por sua vez, representam um distanciamento e uma desconstrução de toda limitação e controle impostos pelo projeto modernizador (PLOEG, 2000).

Portanto, os estilos de agricultura não necessariamente se opõem ao projeto modernizador dominante. Ora derivam e resultam em situações de maior autonomia, ora de maior dependência gerando situações de maior ou menor diversidade e diversificação. Os circuitos curtos de comercialização, $a$ priori, parecem resultar em uma maior autonomia e diversificação. Ademais, o autor trata da capacidade de reação e da capacidade de adaptação da agricultura familiar frente ao pacote tecnológico implantado. A primeira resultaria de uma incapacidade de buscar alternativas, impondo a reprodução de estilos de agricultura marcados pela verticalidade das relações entre agricultores e mercados. A segunda - na qual integramos os circuitos curtos - estaria pautada na possibilidade de buscar certo distanciamento visando à construção de alternativas. Neste caso, é importante considerar que as motivações que levam os agricultores a constituírem determinados estilos de agricultura estão vinculadas ao padrão de desenvolvimento rural predominante em determinado recorte territorial.

Schneider e Menezes (2014) também corroboram com essa perspectiva, ao afirmarem que agricultores familiares não apenas reagem ou se adaptam aos condicionantes externos mas também são capazes de agir de forma propositiva. Diante disso, considera-se que essa ação propositiva e - inclui-se aqui o uso do território decorrente da modernização da agricultura - os estilos de agricultura pautados na capacidade de adaptação, ou então, na construção de alternativas, de modo geral, estão associados ao que ora denominamos de novos usos do território decorrentes dos circuitos curtos de comercialização da agricultura familiar.

Assim sendo, cabe ressaltar que, para além das grandes agroindústrias - muitas delas de capital multinacional-, a constituição dos circuitos curtos de comercialização pode ser vista como um processo de reconfiguração de recursos (produtos coloniais) promovidos pela agricultura familiar em conjunto com suas organizações associativas e com o apoio do poder público. Daí é possível elencar duas formas que podem potencializar a atividade dos circuitos curtos: mercados promovidos pelo Pnae, bem como as feiras livres. Nesse sentido, o produto colonial passa a ser visto pelos agricultores familiares como um produto comercial com um valor de troca e, portanto, como fonte de renda da unidade de produção familiar, levando a um novo uso do território. 
É interessante destacar que no caso do Pnae, no momento em que o governo federal define que uma porcentagem dos recursos destinados a este programa deve ser gasto na agricultura familiar com o intuito de promover o comércio e o consumo local de alimentos, o governo está dando força ao movimento dos circuitos curtos. Os agricultores que produzem nas suas propriedades para comercializar os alimentos nas feiras da cidade, também encontram nessa atividade uma forma de potencializar os circuitos curtos.

De acordo com Renting, Marsden e Banks (2003, 2017), Marsden, Banks e Bristow (2000), os circuitos curtos dizem respeito à reconexão entre produtores e consumidores, socializando e espacializando o alimento nas escalas local ou regional, o que perpassa a construção social de mercados, baseada no reconhecimento por parte do consumidor, da origem do sistema de produção, da confiança e credibilidade.

Nessa perspectiva, o desenvolvimento dos circuitos curtos tem importantes repercussões sobre o território. As estratégias utilizadas pelos agricultores familiares vêm representando mudanças no âmbito interno da organização da unidade familiar de produção, repercutindo na diversificação econômica regional e, não raro, no fortalecimento de sistemas agroecológicos de produção (TRICHES; SCHNEIDER, 2010). Ou seja, o território passa a ter uma nova forma de organização, que se configura como mecanismo de desenvolvimento rural. Assim, a nova forma de uso do território, dada pela agricultura familiar, torna-se promotora de "um modelo mais sustentável, que aproxime a produção de pequenos agricultores familiares e o consumo de alimentos, contribuindo para uma reconexão da cadeia alimentar e uma relação mais estreita" (TRICHES; SCHNEIDER, 2010, p. 2).

Logo, cabe destacar que a agregação de valor do conjunto das atividades dos circuitos curtos de comercialização, em sua maior parte constituída em bases familiares, abrange uma grande diversidade de produtos como milho, mel, leite e derivados, conservas, derivados de cana-de-açúcar, doces e chimias derivados de frutas, sucos de frutas, chás, avicultura de corte e postura, derivados de carne suína etc. Essa característica pode ser mobilizada para contrabalançar, pelo menos em parte, a tendência da especialização dos sistemas convencionais de produção (MIOR, 2005)1.

Mior (2005) destaca que, enquanto boa parte da agroindústria convencional do Oeste Catarinense busca insumos e matérias-primas externas à região (milho e soja do Centro Oeste, por exemplo), a agricultura familiar potencializa a utilização de insumos e matérias-primas locais e regionais, constituindo-se como uma forma particular de desenvolvimento rural. Nesse sentido, a emergência de um conjunto de atividades de agregação de valor pautadas na produção agrícola de pequena escala, vem se constituindo em uma condição fundamental para a concretização de novas
1 A economia agrícola do estado de Santa Catarina, de forma tendencial, vem se tornando dependente de poucas atividades produtivas. A suinocultura, a avicultura e o fumo, por exemplo, contribuem com cerca de $50 \%$ do valor bruto da produção agropecuária de Santa Catarina no ano de 2005 (EPAGRI/CEPA, 2007). 
estratégias de organização do produtor, potencializadoras da economia local e dos circuitos curtos. É neste processo que se constroem novas redes sociais que poderão se constituir nos pilares para a consolidação de redes de aprendizagem e inovação do espaço rural.

Portanto, a partir do que foi exposto, defende-se que a agricultura familiar sinaliza para um maior grau de sustentabilidade no desenvolvimento rural, já que favorece a diversificação das atividades produtivas agrícolas e não agrícolas, utiliza matérias-primas e recursos locais, prioriza a transição para sistemas agroecológicos, empodera os atores sociais e institucionais (MIOR, 2005), o que pode ser potencializado a partir do fomento aos circuitos curtos. Por isso, em seguida, é apresentada uma discussão acerca dos circuitos curtos de comercialização como um novo uso do território.

Os circuitos curtos de comercialização como novos usos do território no Oeste Catarinense: aproximaçôes iniciais

Os circuitos curtos de comercialização, inseridos no contexto acima discutido, configuram uma nova forma de uso do território. Santos e Silveira (2001, p. 27) inferem que o uso do território é determinado e construído pela sociedade, "por intermédio de suas técnicas diversas no tempo e nos lugares”. Dessa forma, partindo da ideia de que os usos do território são diferentes nos diversos momentos históricos, ainda hoje encontramos agricultores que utilizaram o território basicamente para a produção de autoconsumo e venda do excedente. Contudo, no período da modernização da agricultura, de modo geral, o território passou a ser usado como recurso para o cultivo de monoculturas, a partir do uso da tecnologia, dos agrotóxicos e das sementes híbridas e transgênicas que possibilitam o aumento da produtividade agrícola, como sinalizado anteriormente. Assim, vivencia-se na atualidade processos que têm mudado as formas-conteúdos de apropriação (SANTOS, 2005), dominação e uso dos territórios, hoje, marcados também por conflitos territoriais por terra, luta pela vida, por trabalho digno, contra práticas de mercantilização da natureza, entre outros. Nessas mudanças inserem-se também os circuitos curtos de comercialização.

Nesse sentido, François (200, p. 13) contribui para a definição de circuitos curtos ao afirmar que estes são uma forma de comercializar os produtos permitindo "diminuir o número de intermediários entre o produtor e o consumidor". O circuito mais curto é aquele em que o produtor entrega diretamente o seu produto ao consumidor, chamado "venda direta". Esses circuitos constituem capacidade de caracterizar o território e reforçar a especificidade dos produtos. Essas formas de venda, através da ligação mais estreita entre o território, o cliente e o produto, reforçam o caráter de proximidade da produção local, bem como a constituição de novos usos do território. 
A agricultura familiar, nesse sentido, é a principal protagonista na constituição dos circuitos curtos de comercialização e, consequentemente, dos nos usos do território. Os agricultores familiares que não se enquadraram nas exigências tecnológicas que as agroindústrias impuseram, viram-se forçados a buscar estratégias e alternativas, a fim de sobreviver e manterse na agricultura. Para isso, adotaram dinâmicas diferenciadas, as quais se caracterizam por meio de um processo de diversificação de cultivos e atividades na propriedade e fora dela. Os circuitos curtos estão diretamente relacionados a este cenário. Fraçois (2000) defende que as novas tendências do consumo, que levam cada vez mais à procura de produtos saudáveis, naturais, com uma identidade ligada a um território oferecem novas oportunidades de mercado para os produtos das zonas rurais.

A ideia de circuitos curtos não diz respeito somente a distância percorrida pelos alimentos. Segundo Scheneider e Ferrari (2015), as cadeias curtas de alimentos possibilitam um processo de ressocialização ou reespacialização do alimento, possibilitando o julgamento de valor pelo consumidor. Esses novos modelos de comercialização (direta) permitem também a negociação dos melhores preços e a retomada do controle das vendas pelos produtores com a qualificação dos consumidores.

Segundo Schneider e Ferrari (2015), as cadeias curtas apresentam diferentes dimensões, a saber: a) espacial, ao reduzir as distâncias que os alimentos percorrem entre a produção e o consumo; b) social, ao proporcionar o contato face a face entre produtores e consumidores, que resultam em confiança e integração na cadeia; e c) econômica, ao alavancar mercados locais para a produção. Os circuitos curtos podem acontecer através dos produtos produzidos nas pequenas agroindústrias rurais familiares ou em relações face a face, como vendas em domicílio e feiras livres, sejam de produtos da agricultura ou até mesmo de artesanatos (SCHNEIDER; FERRARI, 2015).

Marsden, Banks e Bristow (2000) acrescentam que os circuitos curtos ocorrem quando um produto chega às mãos do consumidor com informações que lhe permitam saber sobre o lugar, o produtor e o sistema de produção, ou seja, onde o produto foi produzido, por quem e de que forma. Para os autores, existem três tipos de cadeias curtas: (i) proximidade espacial: os produtos são produzidos e distribuídos na região específica de produção; (ii) espacialmente estendida: produtos carregados com valores, significados e informações locais e podem ser comercializados fora da região de produção; (iii) face a face: venda direta do produtor para o consumidor, como ocorre nas feiras livres.

Fonseca et al. (2009) destacam enquanto fortalezas dos circuitos curtos a troca de conhecimentos, saberes e sabores entre produtores, entre produtores e consumidores, entre consumidores. Ainda, tem-se a 
2 O Programa Nacional de Alimentação Escolar (Pnae) é a maior e mais antiga política pública no Brasil. Há pouco tempo, "novas diretrizes de execução do Pnae foram estabelecidas a partir da Lei Federal no 11.947 e da Resolução no 38 - Fundo Nacional de Desenvolvimento da Educação (FNDE), promulgadas em julho de 2009. O FNDE realiza os repasses de verbas oriundas do governo federal para a alimentação escolar das escolas estaduais e municipais, com base no número de alunos matriculados na educação básica. possibilidade de exercitar melhor o controle social das qualidades orgânicas e das garantias dos produtos orgânicos identificadas pelos consumidores devido ao envolvimento produtor-consumidor e as organizações de apoio (públicas, privadas ou da sociedade civil); qualidade esta que se expressa em produtos frescos e com preços menores que nas redes do grande varejo devido à venda direta produtor.

Conforme Darolt et al. (2016), uma das especificidades dos circuitos curtos é o questionamento de alguns princípios básicos do sistema convencional, como a homogeneização, a padronização de produtos e o grande número de intermediários na comercialização em grandes distâncias. Nesse sentido, as redes alternativas propõem novos princípios de troca, relocalização dos alimentos, retomam valores, tradições e novos tipos de relações entre produtores e consumidores. Defendem os autores, a capacidade dos circuitos curtos gerarem mudanças estruturais em uma escala maior. Esses mercados podem contribuir para uma transformação das relações de poder no âmbito dos sistemas alimentares, incluindo maior participação de consumidores e produtores na definição dos modos de produção, troca e consumo, o que remete à autonomia.

Assim, é importante inferir que ao favorecer um contato direto com o produtor (ou o território, através de um estabelecimento local), a venda direta tem possibilidade de explicar a especificidade dos produtos ao consumidor e de valorizá-los diretamente. Através dos produtos locais, é o território e o seu potencial que são valorizados. A presença destes produtos, assinalada expressamente no comércio, constitui um meio para que o público - visitantes e população local - ganhe consciência da própria existência do território, do seu valor, da sua cultura e dos seus produtos específicos. Portanto, vale recorrer a Santos e Silveira (2001, p. 27), ao defenderem que o uso do território é determinado e construído pela sociedade, "por intermédio de suas técnicas diversas no tempo e nos lugares”. Isto é, são os agricultores das pequenas propriedades rurais que impregnam um novo uso do território, a partir de suas técnicas, no tempo e nos lugares. E os consumidores, ao valorizarem produtos coloniais, muitos agroecológicos, também fazem parte dessas novas formas e conteúdos territoriais.

Dito isto, é possível citar, enquanto exemplos de circuitos curtos, aqueles promovidos pelo Pnae e pelas feiras coloniais identificados na região oeste de Santa Catarina.

O Pnae ${ }^{2}$, assim como o PAA, são potencializadores dos circuitos curtos, uma vez que promovem o comércio local sem a participação de intermediários. No caso do Pnae, cabe destacar que o art. 14 da Lei Federal no 11.947 resolve que, no mínimo, 30\% do total dos recursos despendidos à alimentação escolar sejam destinados à compra de alimentos, preferencialmente orgânicos, produzidos pela agricultura familiar, local, 
regional ou nacional. "O Programa, a partir destas diretrizes, tornou-se um importante segmento institucional para aquisição de alimentos da agricultura familiar" (SARAIVA et al., 2013, p. 928).

Além disso, observa-se uma considerável variedade de alimentos produzidos pela agricultura familiar destinada à alimentação escolar, tal como aponta a Tabela 1, para municípios selecionados de Santa Catarina.
3 Joinville, Florianópolis, Blumenau, Chapecó, Lages, Caçador, Gaspar, Mafra, São Miguel do Oeste, Laguna, Ibirama, Monte Carlo, Faxinal dos Guedes, Canelinha, Passo de Torres.

Tabela 1 - Diversidade de alimentos produzidos pela agricultura familiar e comercializados pelo mercado do Pnae em municípios selecionados ${ }^{3}$ de Santa Catarina

\begin{tabular}{|c|c|c|c|c|c|c|}
\hline $\begin{array}{l}\text { Legumes/ } \\
\text { Hortaliças }\end{array}$ & Frutas & Carnes & Lácteos & Grãos & Panifícios & Outros \\
\hline \multirow{4}{*}{$\begin{array}{l}\text { Abóbora paulista } \\
\text { Abobrinha } \\
\text { Vagem de forma }\end{array}$} & Abacaxi perola & \multirow{4}{*}{$\begin{array}{l}\text { Coxa e } \\
\text { sobrecoxa de } \\
\text { frango } \\
\text { Frango inteiro } \\
\text { congelado }\end{array}$} & \multirow{2}{*}{$\begin{array}{l}\text { Iogurte de } \\
\text { coco }\end{array}$} & Lentilha & Pão Caseiro & \multirow{2}{*}{$\begin{array}{l}\text { Melado de } \\
\text { cana }\end{array}$} \\
\hline & \multirow{2}{*}{$\begin{array}{l}\text { Banana (branca, } \\
\text { caturra, petiça). }\end{array}$} & & & Milho-verde & Pão sovado & \\
\hline & & & Iogurte de & espiga Milho & Massa de & Ovos \\
\hline & Amora & & morango & de pipoca & lasanha & Ovo branco \\
\hline Acelga & Abacate & Salsicha fresca & $\begin{array}{c}\text { Leite } \\
\text { pasteurizado }\end{array}$ & Feijão carioca & Grostoli & Ovos de \\
\hline Alho & Laranja & 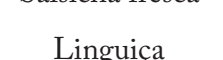 & & Feijão preto & Farinha de fubá & granja \\
\hline मानि & (Lima, Pera) & Lingurça & pasteurizado & Arroz branco & Farinha de trigo & Ovos de \\
\hline Batata doce & Goiaba vermelha & $\begin{array}{l}\text { Carne moida } \\
\text { Carne suína }\end{array}$ & tipo $\mathrm{C}$ & Arroz branco & Cuca caseira & $\begin{array}{l}\text { galinna } \\
\text { vermelhos }\end{array}$ \\
\hline Batata inglesa & Maçã (Fuji) & Carne suina & Queijo & agulhinha & Bolacha caseira & Mel \\
\hline $\begin{array}{l}\text { Beterraba } \\
\text { Brócolis }\end{array}$ & Mamão formosa & $\begin{array}{l}\text { Carne suína em } \\
\text { cubos }\end{array}$ & $\begin{array}{l}\text { fatiado } \\
\text { Leite UHT }\end{array}$ & $\begin{array}{c}\text { Pinhão } \\
\text { Amendoim }\end{array}$ & $\begin{array}{c}\text { (manteiga, } \\
\text { glacê) }\end{array}$ & Tortei de \\
\hline Cebola & Melancia & Paleta com e & integral longa & Feiião em & giace) & moranga \\
\hline Cedora & Tangerina & sem osso & vida & vagem & Cuca alenta & Lasanha de \\
\hline Cenoura & Morango & Pernil & Bebida láctea & & Bolacha de nata & frango \\
\hline Chuchu & Pera & Tortei de & Queijo & & Macarrão & $\begin{array}{l}\text { Açúcar } \\
\text { mascavo }\end{array}$ \\
\hline Couve-flor & Melão & moranga & colonial & & caseiro & mascavo \\
\hline Couve manteiga & Laranja (Lima, & $\begin{array}{l}\text { Salame pré- } \\
\text { cozido }\end{array}$ & $\begin{array}{c}\text { inteiro } \\
\text { Queijo tipo }\end{array}$ & & $\begin{array}{c}\text { Biscoito } \\
\text { amanteigado }\end{array}$ & $\begin{array}{l}\text { Doce de fruta } \\
\text { cremoso }\end{array}$ \\
\hline Pepino & Valência) & Peito de frango & colonial & & com linhaça & Polpa de fruta \\
\hline Repolho & Kiwi & & fatiado & & Pão de trigo & Suco de fruta \\
\hline Batata Baroa & Manga & $\begin{array}{l}\text { Linguiça } \\
\text { toscana }\end{array}$ & Queijo & & Mini pizza & Chá orgânico \\
\hline Tomate & Maracujá & Carne bovina & & & Bolacha de fubá & Filé de peixe \\
\hline Agrião & Lima & & & & Bolacha pintada & Tilápia \\
\hline Pimentão & Limão (Taity) & & & & & Sopa de peixe \\
\hline Aipim & Caqui & & & & & congelada \\
\hline Cenoura & Bergamota & & & & & \\
\hline Chicória & Uva & & & & & \\
\hline Rabanete & Tangerina Pocan & & & & & \\
\hline Rúcula & & & & & & \\
\hline Couve-folha & & & & & & \\
\hline
\end{tabular}

Fonte: Adaptado de Chamadas Públicas das prefeituras dos municípios selecionados - 2012 e 2013. 
É possível visualizar, pela diversidade de alimentos requeridos pelas chamadas públicas, que o mercado institucional da alimentação escolar é capaz de impregnar novos usos sobre o território, apontando para reflexos socioculturais, econômicos e ambientais sobre o quadro de vida dos agricultores familiares e dos alunos das escolas beneficiados com a política. Há geração de renda para os agricultores, além do fornecimento de alimentos frescos e adequados à cultura alimentar local/regional.

Podemos citar, ainda, a atividade das feiras livres que ocorrem na cidade de Chapecó, as quais potencializam os circuitos curtos ao aproximarem os agricultores feirantes dos consumidores, garantindo uma alternativa de renda aos produtores e uma oportunidade de escolha para os consumidores urbanos. Não necessariamente o consumidor da cidade precisa adquirir frutas e hortaliças nos supermercados, os quais, em parte, são oriundos de outros estados.

Como atestam Fontana e Lima (2018), as feiras representam mais do que um mercado, são também lugares de interação, sobretudo, nas pequenas e médias cidades. "Nas feiras estão à disposição produtos de boa qualidade - talvez não os mais bonitos e maiores - porém os mais saudáveis. Saudáveis pela sustentabilidade econômica, social e ambiental proporcionada pela agricultura familiar. Saudáveis pela valorização do comércio mais justo, proporcionado pela característica de comercialização das redes curtas, quando os agricultores e os "fregueses" entram em acordo sobre o preço de algum produto".

Em 2014, Chapecó contava com dez pontos de feiras, estando dois localizados no centro da cidade e os demais nos bairros. São em torno de 120 famílias que comercializam seus produtos nas dez feiras existentes (POZZEBOM, 2015). Vale ressaltar que Chapecó possui atualmente uma população superior a 183.000 habitantes. Nesse sentido, considerando que a procura, em geral é maior que a oferta de produtos nas feiras (POZZEBOM, 2015) há um potencial a ser explorado no que se refere a este circuito curto.

Como atestado em Pozzebom, Rambo e Gazolla (2018), as feiras livres são um dos principais canais curtos de abastecimento agroalimentar da população brasileira. Elas são importantes para os agricultores, pois cumprem os papéis de escoar a produção, garantir melhores preços e possibilitar a aproximação com seus consumidores. Do lado do consumo, aproximam consumidores dos agricultores, religando-os em circuitos comerciais, mas também simbólicos e de construção da sociabilidade. Os consumidores têm acesso aos alimentos que fazem parte de seus repertórios culturais e hábitos de consumo locais, uma vez que a produção é realizada pela agricultura familiar local. 
A tabela dois demonstra a diversidade de alimentos produzidos e comercializados por agricultores familiares feirantes selecionados do município de Chapecó.

Tabela 2 - Alimentos produzidos pelos agricultores familiares feirantes do município de Chapecó/SC

\begin{tabular}{|c|c|c|}
\hline Alimentos de origem vegetal & Quantidade total produzida $/ \mathbf{a n o}^{4}$ & $\begin{array}{c}\text { Quantidade total de } \\
\text { autoconsumo familiar/ano }\end{array}$ \\
\hline Batata - doce & $6.200 \mathrm{Kg}$ & $750 \mathrm{Kg}$ \\
\hline Feijão & $1.840 \mathrm{Kg}$ & $140 \mathrm{Kg}$ \\
\hline Mandioca & $17.800 \mathrm{Kg}$ & $1950 \mathrm{Kg}$ \\
\hline Milho & $10.000 \mathrm{Kg}$ & $200 \mathrm{Kg}$ \\
\hline Alface & 34.000 unidades & 1912 unidades \\
\hline Beterraba & $7.400 \mathrm{Kg}$ & $256 \mathrm{Kg}$ \\
\hline Cenoura & $4.400 \mathrm{Kg}$ & $232 \mathrm{Kg}$ \\
\hline Couve & 3.600 unidades & 68 unidades \\
\hline Salsa & 2.550 maços & 96 maços \\
\hline Repolho & 22.700 unidades & 16 unidades \\
\hline Tomate & $6.000 \mathrm{Kg}$ & $360 \mathrm{Kg}$ \\
\hline Radiche & 1.800 maços & 96 maços \\
\hline Rúcula & 6.100 maços & 336 maços \\
\hline Couve-flor & 1.280 unidades & 52 unidades \\
\hline Pimentão & $1.240 \mathrm{Kg}$ & $98 \mathrm{Kg}$ \\
\hline Brócolis & 3.750 unidades & 60 unidades \\
\hline Cebolinha & 2.480 maço & 52 maço \\
\hline Pepino & $3.000 \mathrm{Kg}$ & $100 \mathrm{Kg}$ \\
\hline Alimentos de origem animal & Quantidade total produzida & $\begin{array}{c}\text { Quantidade total de } \\
\text { autoconsumo familiar/ano }\end{array}$ \\
\hline Carne suína & $12.000 \mathrm{Kg}$ & $100 \mathrm{Kg}$ \\
\hline Salame & $360 \mathrm{Kg}$ & $30 \mathrm{Kg}$ \\
\hline Leite & 8.000 litros & 730 litros \\
\hline Ovos & 300 bandejas & 25 bandejas \\
\hline
\end{tabular}

Fonte: Pozzebom (2015).

Além de ser possível observar a diversidade de alimentos produzidos e comercializados nas feiras, é possível perceber que há uma relação sinérgica entre produção para autoconsumo e produção para as feiras. Este circuito curto potencializa, assim, a segurança alimentar e nutricional (SAN) tanto dos agricultores quanto dos consumidores, entendendo por SAN

[...] a realização do direito de todos ao acesso regular e permanente a alimentos de qualidade, em quantidade suficiente, sem comprometer
4 As quantidades correspondem ao total de produção, ou seja, trata-se do total de alimentos produzidos para autoconsumo, comercialização e para alimentação de animais.

5 Autoconsumo da família exclui a alimentação fornecida aos animais. 
o acesso a outras necessidades essenciais, tendo como base práticas alimentares promotoras da saúde que respeitem a diversidade cultural e que sejam ambiental, cultural, econômica e socialmente sustentáveis. (MALUF, 2007, p. 17).

Reforçam Fontana e Lima (2018) que a feira é tão importante para o agricultor, que comercializa e se doa a cada dia de feira, como para aqueles que a frequentam e consomem os produtos ali expostos. Dar valor e acreditar que é possível consumir alimentos saudáveis em uma era onde tudo que se pensa já está industrializado é audacioso e pertinente. As rotinas atarefadas, a falta de tempo para tudo justifica o não se alimentar de maneira saudável, com alimentos preparados na hora, assim como se manter agricultor que produz em pequena escala alimentos que vão à mesa na turbulência do cotidiano, no qual grandes empresas e o sistema que conduz as produções são de monopólios, tornam-se desafios e instigam os envolvidos.

Specht et al. (2018) corroboram que as feiras livres têm se mostrado como um canal diferenciado de comercialização para abastecimento de alimentos. Além da sua função econômica de agregar renda ao produtor encurtando a cadeia produtiva, mostra-se como um espaço de socialização diferenciado, incorporando no cotidiano a diversidade regional e as tipicidades do espaço onde funciona.

\section{Considerações finais}

Com este trabalho, buscamos contribuir para as discussões sobre agricultura familiar, suas estratégias de reprodução social e econômica e assim, sua contribuição para os processos de desenvolvimento rural. Por ser uma ciência que se ocupa do estudo das transformações do espaço geográfico, a Geografia, a partir da abordagem territorial, em especial, na análise dos usos do território, pode auxiliar na compreensão acerca do papel dos circuitos curtos de comercialização, no desenvolvimento rural e na constituição de novos usos do território.

Ao analisarmos a dinâmica do espaço rural brasileiro, em especial na região Sul, podemos observar um uso do território anterior à Revolução Verde, que se caracterizava por uma pequena produção mercantil. Este uso se dava pela produção diversificada para subsistência e a venda do excedente. Como demonstrado no artigo, este processo exclui parte considerável dos pequenos agricultores. Esses, por sua vez, acabam tendo que encontrar formas alternativas de sobrevivência em meio ao processo de exclusão. Pode-se, assim, observar diferentes exemplos de capacidades de reação (PLOEG, 2000) dos agricultores familiares, expressos no Oeste Catarinense por meio dos circuitos curtos de comercialização via mercados institucionais, feiras livres e outras formas de venda direta. Esses circuitos 
curtos de comercialização, não raramente, atribuem novas funções a antigas formas (SANTOS, 1996), ou seja, produtos que antes eram destinados ao autoconsumo, passam a ser também comercializados, e comumente se tornam a principal fonte de renda familiar.

Os circuitos curtos de comercialização tendem a contribuir para a promoção do desenvolvimento rural em suas diferentes dimensões. Economicamente representam uma alternativa de renda para os agricultores familiares, apresentando, enquanto aspecto positivo, uma melhor remuneração ao agricultor, uma vez que exclui o atravessador em razão de a venda ser direta. Socialmente, tendem a valorizar a cultura alimentar local/regional, por serem produzidos para o mercado local, produtos típicos, contribuindo também para a SAN local/regional. Ambientalmente, contribuem com a manutenção da biodiversidade, uma vez que os circuitos curtos despendem menos energia para o transporte dos produtos, além de fomentarem uma produção diversificada nas propriedades, tanto incentivada pelas feiras livres, quanto pelo mercado institucional do Pnae.

Nessa perspectiva, os circuitos curtos de comercialização, configuram uma nova forma de uso do território. Santos e Silveira (2001, p. 27) inferem que o uso do território é determinado e construído pela sociedade, "por intermédio de suas técnicas diversas no tempo e nos lugares”. Ou seja, na medida em que a agricultura familiar cria e recria seu espaço de produção e comercialização através da venda em pequenas distâncias e de forma direta ao consumidor, potencializa uma nova forma mais sustentável de uso do território. Nesse sentido, ainda é preciso avançar no fomento e na formulação de políticas públicas que impulsionem esse tipo de comércio de alimentos.

\section{Referências}

BALSAN, R. Impactos Decorrentes da Modernização da Agricultura Brasileira. Campo e Território - Revista de geografia agrária, v. 1, n. 2, p. 123-151, 2006.

CAMPOS, G. L. de. Agricultura familiar, gerenciamento ambiental e agroecologia: algumas questões provocativas a serem pesquisadas. In: TEDESCO, J. C. (Org.). Agricultura Familiar: realidades e perspectivas. Passo Fundo: EDIUPF, 1999.

DAROLT, M. R. et al. Redes alimentares alternativas e novas relações produçãoconsumo na França e no Brasil. Ambiente \& Sociedade, São Paulo v. 19, n. 2, p. 1-22 abr./jun. 2016.

EPAGRI/CEPA. Centro de Socioeconomia e Planejamento Agrícola de Santa Catarina.Síntese Anual da Agricultura Catarinense, 2007. Disponível em: http:// www.epagri.sc.gov.br. Acesso em: 18 nov. 2018.

ESPÍNDOLA, C. J. As Agroindústrias no Brasil: O Caso Sadia. Chapecó: Grifos, 1999. 
FONSECA, M. F. A. et al. Características, estratégias, gargalos, limites e desafios dos circuitos curtos de comercialização de produtos orgânicos no Rio de Janeiro: as feiras. Revista Brasileira de Agroecologia, v. 4, n. 2, p. 2599-2602, 2009.

FONTANA, A. P. C.; LIMA, R. de S. As feiras da agricultura familiar como território de práticas alimentares e sociabilidades: compreendendo a relação feirante - freguês. In: THIRD INTERNACIONAL CONFERENCE AGRICULTURE AND FOOD IN NA URBANIZING SOCIETY, 17-21 set. 2018, Porto Alegre. Anais eletrônicos... Porto Alegre: 2018. Disponível em: https://drive.google.com/file/d/1WXDawGsmp4PAyYAHuey7bLBmgrVRhx wo/view. Acesso em: 12 maio 2019.

FRANÇOIS, M. Comercializar os produtos locais: circuitos curtos e circuitos longos. Inovação no meio rural. Caderno no 7. [s. 1.]: Observatório Europeu LEADER, jul. 2000.

FREDERICO, S. Modernização da agricultura e uso do território: a dialética entre o novo e o velho, o interno e o externo, o mercado e o Estado em áreas do cerrado. GeoUsp - espaço e tempo, n. 33 (Especial), p. 218-232, 2013.

GRAZIANO DA SILVA, J.; DEL GROSSI, M. E. O Novo Rural Brasileiro. Debates Socioambientais, São Paulo, v. 7, n. 14, p. 16-18, 2000.

HAESBAERT, R. O mito da desterritorialização e as "regiões-rede". In: ENCONTRO DE GEÓGRAFOS DA AMÉRICA LATINA, 10., 2005, São Paulo. Anais... São Paulo: Universidade de São Paulo, 2005. p. 6774-6792.

HENTZ, C. O agronegócio no oeste catarinense e seus desdobramentos no consumo produtivo de Chapecó-SC. 2014. 71 f. Trabalho de Conclusão de Curso (Licenciatura em Geografia) - Universidade Federal da Fronteira Sul, Chapecó, 2014.

HESPANHOL, R. A. de M. Produção familiar: perspectivas de análise e inserção na Microrregião Geográfica de Presidente Prudente. 2003. 354 f. Tese (Doutorado em Geografia) - Programa de Pós-Graduação em Geografia, Universidade Estadual Paulista "Júlio de Mesquita Filho", Rio Claro, 2003.

MALUF, R. S. J. Segurança Alimentar e Nutricional. Petrópolis: Vozes, 2007.

MARSDEN, T.; BANKS, J.; BRISTOW, G. Food suply chain approaches: exploring their role in rural development, Sociologia Ruralis, v. 40, n. 4, p. 424$438,2000$.

MIOR, L. C. Agricultores familiares, agroindústrias e redes de desenvolvimento rural. Unochapecó, Editora Argos, 2005.

PLOEG, J. D. van der et al. Rural Development: From Practices and Policies towards Theory. Sociologia Ruralis, v. 40, n. 4, p. 391-408, oct. 2000.

POZZEBON, L.; RAMBO, A. G.; GAZOLLA, M. As Cadeias Curtas das Feiras Coloniais e Agroecológicas Autoconsumo e Segurança Alimentar e Nutricional. Desenvolvimento em Questão, Unijuí, 16, n. 42, jan./mar. 2018.

POZZEBON, L. Segurança alimentar e nutricional e autoconsumo entre agricultores das feiras de produtos coloniais e agroecológicos de ChapecóSC. 2015. 27 f. Trabalho de Conclusão de Curso (Especialização em Segurança Alimentar e Nutricional) - Universidade Federal da Fronteira Sul, Chapecó, 2015. 
RENTING, H.; MARSDEN, T. K.; BANKS, J. Understanding alternative food networks: exploring the role of short food supply chains in rural development. Environment and Planning A, v. 35, n. 3, p. 393-411, 2003.

RENTING, H.; MARSDEN, T. K.; BANKS, J. Compreendendo as redes alimentares alternativas: o papel das cadeias curtas de abastecimento de alimentos no desenvolvimento rural. In: GAZOLLA, M.; SCHNEIDER, S. (Org.). Cadeias curtas e redes agroalimentares alternativas: negócios e mercados da agricultura familiar. Porto Alegre: Editora da UFRGS, 2017. p. 27-52.

RECHE, D. A influência do capital agroindustrial na distribuição socioespacial urbana do município de Chapecó no Sul do Brasil. In: COLÓQUIO INTERNACIONAL DE GEOCRITICA, 10., 2008, Barcelona. Anais... Barcelona, 2008.

SANTOS, M. A natureza do espaço: técnica e tempo, razão e emoção. São Paulo: Hucitec, 1996.

SANTOS, M. O dinheiro e o território. In: SANTOS, M. et al. Território, territórios: ensaios sobre ordenamento territorial. Rio de Janeiro: Lamparina, 2007. p.13-21.

SANTOS, M. O retorno do território. In: SANTOS, M. Territorio y movimentos sociales. OSAL: Observatorio Social de América Latina, año 6, n. 16. Buenos Aires: CLASCO, 2005. p. 251-261.

SANTOS, M.; SILVEIRA, M. L. O Brasil: território O Brasil e sociedade no início do século XXI. Rio de Janeiro: Record, 2001.

SARAIVA, E. B. et al. Panorama da compra de alimentos da agricultura familiar para o Programa Nacional de Alimentação Escolar. Ciênc. saúde coletiva [online], v. 18, n. 4, p. 927-935, 2013.

SCHNEIDER, S.; FERRARI, D. L. Cadeias curtas, cooperação e produtos de qualidade na agricultura familiar: o Processo de Relocalização da Produção Agroalimentar em Santa Catarina. Organizações Rurais \& Agroindustriais, v. 17, n. 1, p. $56-71,2015$.

SCHNEIDER,S.;MENEZES,M.A.Inovação e atores sociais.In: SCHNEIDER, S.; MENEZES, M.; SILVA, A. G. da; BEZERRA, I. (Org.). Sementes e brotos da transição: inovação, poder e desenvolvimento em áreas rurais do Brasil. Porto Alegre: UFRGS, 2014. p. 13-26.

SPECHT, S. et al. É dia de fazer feira na Universidade: análise do perfil do consumidor da Polifeira - UFSM. In: THIRD INTERNACIONAL CONFERENCE AGRICULTURE AND FOOD IN NA URBANIZING SOCIETY, 17-21 set. 2018, Porto Alegre. Anais eletrônicos... Porto Alegre: 2018. Disponível em: https://drive.google.com/file/d/11L21ehybfCeegHyyn3Njr IS7UHQFztmJ/view. Acesso em: 10 maio 2019.

TRICHES, M. R.; SCHENEIDER, S. Reconstruindo o “elo perdido": a reconexão da produção e do consumo de alimentos através do programa de alimentação escolar no município de Dois Irmãos (RS). Segurança alimentar e nutricional, Campinas, v. 17, n. 1, p. 1-15, 2010.

Submetido em: 04/06/2018

Aceito em: 31/05/2019 


\title{
SHORTS CIRCUITS OF MARKET AND NEW USES OFTHETERRITORY: CONSIDERATIONS ABOUT PNAE AND THE FREE FAIRS
}

\begin{abstract}
The agriculture modernization process, especially in Brazil, has embed on the territory, new uses, and has pressed many family farmers to find new alternatives of production and income generation. The debate about the recognition of the role of food short supply's promoted by family farmers, their capacity to promote new uses of the territory, and their repercussions on rural development, is inserted in this exclusion context and appears as an alternative to the standard model of technification of rural areas. Thus, two examples of food short supply's existing in Santa Catarina will be present, indicating how these circuits promote new uses of the territory. The cases refered to concern the markets promoted by the Programa Nacional de Alimentação Escolar (PNAE), as well as the free fair of Chapecó. With these examples, we wish to draw attention to the importance of different formats of food short supply's, which initially demonstrate that they are promoting agricultural and non-agricultural uses in rural areas, adding to the local development dynamics, the potential of the resource base through productive diversification and income generation. This implies the recognition and strengthening of the rural area economic, social and environmental sustainable.
\end{abstract}

Keywords: Family farmer. Short circuits. Territory use. Food production.

\section{CIRCUITOS CORTOS DE COMERCIALIZACIÓN Y NUEVOS USOS DEL TERRITORIO: CONSIDERACIONES SOBRE EL PNAE Y LAS FERIAS LIBRES}

\begin{abstract}
Resumen
El proceso de modernización de la agricultura, sobretodo en Brasil, imprimió sobre el territorio, nuevos usos, y presionó muchos agricultores familiares a ubicar nuevas alternativas de producción y generación de renda. La discusión acerca del reconocimiento del papel de los circuitos cortos de comercialización, promovidos por agricultores familiares, su capacidad de promover nuevos usos del territorio, y sus reflexos sobre el desarollo rural, está inserido en esto contexto de exclusión y surge como una alternativa al modelo estandarizado de tecnificación del espacio rural. Así, seran apresentados adelante, dos ejemplos de circuitos cortos de comercializción presentes en el estado de Santa Catarina, apontando como estos circuitos promoven nuevos usos del territorio. Los casos referidos hacen referencia a los mercados promovidos por lo Programa Nacional de Alimentación Escolar (Pnae), así como las ferias libres en la ciudad de Chapecó. Con estos ejemplos, pretendemos llamar atención para la importancia de distintos formatos de circuitos cortos de comercialización, los cuales demonstran inicialemente, que están promovendo usos agrícolas y no agrícolas en el espacio rural, agregando a las dinamicas locales de desarollo, capacidades potencializadoras de la base de los recursos mediante la diversificación productiva y la generación de renda. Eso implica en el reconocimiento y fortalecimiento de un espacio rural más diversificado y sustentable económica, social y ambientalmente.
\end{abstract}

Palabras clave: Agricultura familiar. Circuitos cortos. Usos del territorio. Producción de alimentos. 